\title{
Diagnostic value of cardiac magnetic resonance imaginng in patients with suspected acute myocardial infarction without significant coronary stenosis
}

\author{
Annachiara Aldrovandi', Filippo Pigazzani, Diego Ardissino \\ From 18th Annual SCMR Scientific Sessions \\ Nice, France. 4-7 February 2015
}

\section{Background}

The aim of the study is to evaluate the incremental diagnostic value of cardiac magnetic resonance (CMR) in patients (pts) with suspected acute myocardial infarction (AMI) without significant coronary stenosis at coronary angiography.

\section{Methods}

One hundred forty six consecutive pts (age $61 \pm 14$, 83 [57\%]) females) with suspected AMI and normal coronary arteries or nonobstructive coronary artery disease at coronary angiography were enrolled. Suspected AMI was defined as typical chest pain lasting $>20$, electrocardiographic (EKG) changes and increased cardiac enzymes (troponin I $>99$ th percentile and creatine kinase MB levels more than twice the upper normal limit). All pts underwent CMR $6.2 \pm 5.7$ days after admission using a $1.5 \mathrm{~T}$ MRI system with cine imaging with breath-hold steadystate free-precession sequences, T2 imaging and late enhancement imaging after gadolinium injection (LGE). The image analysis included: presence of myocardial edema on T2 images; presence, localization and pattern of distribution of LGE.

\section{Results}

The admission EKG showed ST elevation in 34 pts (23\%). Median peak troponin I and peak CK MB values were $6.5 \pm 13.8 \mathrm{ng} / \mathrm{ml}$ and $32.2 \pm 49.2 \mathrm{ng} / \mathrm{ml}$ respectively. Mean ejection fraction was $53 \% \pm 10 \%$. LGE was present in $64(45 \%)$ pts and edema in 41 (28\%) pts. LGE distribution was anterior in 27 pts, lateral in 28 pts and inferior in 30 pts. Peak Troponin I value was significantly higher in pts with LGE on CMR imaging compared to those without LGE $(9.9 \pm 16.1 \mathrm{ng} / \mathrm{ml}$ vs $3.8 \pm 11.4 \mathrm{ng} / \mathrm{ml})$ After analyis of CMR images, an acute myocardial infarction was confirmed in 42 pts, while CMR findings suggested myocarditis in 20 pts, apical ballooning in 20 pts, hypertrophic cardiomyopathy in 3 pts.

\section{Conclusions}

CMR provides incremental diagnostic value in a population of pts with suspected acute coronary syndrome without obstructive coronary stenosis at coronary angiography, either by confirming the initial diagnosis or suggesting a different diagnosis. However a portion of patients do not show any LGE at CMR, probably due to the low level of released Troponin I.

\section{Funding}

No funding.

Published: 3 February 2015

doi:10.1186/1532-429X-17-S1-P153

Cite this article as: Aldrovandi et al.: Diagnostic value of cardiac magnetic resonance imaginng in patients with suspected acute myocardial infarction without significant coronary stenosis. Journal of Cardiovascular Magnetic Resonance 2015 17(Suppl 1):P153. 